Research Article, Issue 1
AMECJ
Analytical Methods in Environmental Chemistry Journal

\title{
In-vitro extraction and separation of copper ions from human blood samples based on amoxicillin/clavulanic acid by ultrasound assisted- dispersive centrifuge liquid-liquid micro extraction
}

\author{
", Jamileh Esmaeilia,b, Samira Shirooie ${ }^{\mathrm{c}}$ and Azam Bakhtiarian ${ }^{\mathrm{d}}$ \\ ${ }^{a}$ Ph.D Student in Department of Biology, School of Basic Science, Science and Research Branch, Islamic Azad University, Tehran, Iran \\ ${ }^{b}$ Department of Pharmacology, Tehran University of Medical Sciences \\ ${ }^{c}$ Sciences Research center, Health Institute, Kermanshah University of Medical Sciences, Kermanshah, Iran \\ *,d Department of Pharmacology Tehran University of medical Sciences
}

\begin{abstract}
A R T I C L E I N F O:
Received 18 Nov 2019

Revised form 9 Jan 2020

Accepted 12 Feb 2020

Available online 30 Mar 2020

Keywords:

Copper,

Separation,

Human blood,

Amoxicillin/clavulanic acid,

Ultrasound assisted-dispersive centrifuge

liquid-liquid micro extraction
\end{abstract}

\begin{abstract}
A B S T R A C T
The low concentration of copper $\left(\mathrm{Cu}^{2+}\right)$ can be effected on the central nervous system (CNS) and caused to multiple sclerosis (MS). Although many antibiotics can treat the bacterial infections but some of antibiotics decrease essential metal concentrations in human body and must be controlled by determining. In this study, in-vitro extraction of copper $\left(\mathrm{Cu}^{2+}\right)$ with amoxicillin/clavulanic acid (AMOXC) has been studied due to interacting with metals. By procedure, $\mathrm{Cu}^{2+}$ ions were separated from blood samples by ultrasound assisted-dispersive centrifuge liquid-liquid micro extraction (USA-DC-LLME). The mixture of AMOXC (0.01 $\mathrm{g}$ ), ionic liquid ([BMIM][PF6]) and acetone injected to $10 \mathrm{ml}$ of serum blood sample at human $\mathrm{pH}=7.2$. After extraction, the concentration of $\mathrm{Cu}^{2+}$ ions was determined by flame atomic absorption spectrometry (F-AAS). The LOD, enrichment factor (EF), linear range (LR) and working range (WR) were obtained 6 $\mu \mathrm{g} \mathrm{L}-1,9.92,0.018-0.5 \mathrm{mg} \mathrm{L}^{-1}$ and $0.02-2.58 \mathrm{mg} \mathrm{L}^{-1}$, respectively $(\mathrm{RSD}<1.1 \%)$. The validation of technology was confirmed by ICP and spiking samples.
\end{abstract}

\section{Introduction}

Copper $(\mathrm{Cu})$ acts as a main co-factor in humans and enter into cuproenzymes that catalyze electron transfer reactions (ETR) required for cellular respiration, iron oxidation, neurotransmitter biosynthesis, antioxidant, peptide amylation. The $\mathrm{Cu}$ intake has been associated with toxic effects in humans include influenza-like syndrome, hemolysis and kidney failure due to $\mathrm{Cu}$ sulfate intake [1]. $\mathrm{Cu}$ exists in blood plasma in $\mathrm{Cu}$ bound to caeruloplasmin $(65-71 \%)$ and convert the iron

\footnotetext{
*Corresponding Author: Azam Bakhtiarian

Email: bakhtiar12@yahoo.com

https://doi.org/10.24200/amecj.v3.i01.94
}

$\mathrm{Fe}^{2+}$ into $\mathrm{Fe}^{3+}$ which was bonded to transferrin [2] Copper enter to biochemical reactions and human physiology. In biological matrix such as plasma, copper complex to proteinsas caeruloplasmin and albumin or amino acids [3]. The defect of central nervous system caused to multiple sclerosis (MS) disease in human due to demyelination of nerve fibers of the brain and spinal cord. Based on previous studies, the genetic, immunological and environment factors have main source for creating MS in humans with disability. But, the environment factors such as heavy metals such as copper, zinc, cadmium and lead has significant role in MS [5, 6]. The deadline of time exposure of heavy metals in 
human blood samples depended to kind of heavy metals and chorionic/acute exposure (cadmium was seen in blood up to 1 hour as acute exposure). In chorionic exposure the concentration of heavy metals can be followed in nail or hair. Copper used for many products as an essential element in nature and copper has concentration between $80-180 \mu \mathrm{g} \mathrm{dL}^{-1}$ in blood of human adults (Mean=1.5 $\mathrm{mg} \mathrm{L}^{-1}$ ). Copper exposure in industry occurs primarily through inhaled particulates and according to studies, copper can be a cause of the pathogenesis of MS [6]. The value of copper $\left(\mathrm{Cu}^{2+}\right)$ effect on the central nervous system (CNS) and reducing of their concentration caused to numerous CNS disorders such as multiple sclerosis (MS), Wilson disease, Alzheimer and Parkinson's diseases [7-9]. Also, some of antibiotics caused to decrease essential metals such as $\mathrm{Zn}^{2+}$ and $\mathrm{Cu}^{2+}$ in human body. So, in present of antibiotics, determination of $\mathrm{Zn}^{2+}$ and $\mathrm{Cu}^{2+}$ in human matrixes is very important. Some receptors such as $\beta$-ketoenolbipyridine and ketoenol-pyrazole were functioned on silica hybrid adsorbent and other sorbents [10, 11]. For determination of copper the different analytical techniques such as, ET-AAS [12, 13], ion selective electrode, Square wave $\square$ adsorptive anodic stripping voltammetric (SW $\square$ ASV) [14] and flame atomic absorption spectrometry (F-AAS) [15] were used in different samples such as blood, waters and tissues(fish)[16]. High interferences in human blood are main problems for determination copper by instruments. So, sample preparation must be used before analysis by instruments. The different procedures such as, cloud point extraction (CPE)[9], liquid-liquid extraction (LLE) [15],solidphase extraction (SPE) in human biological fluid (blood, serum and urine) [17,18-22] and dispersive liquid-liquid microextraction (D-LLME) based on ionic liquids (IL) $[23,24,15]$ were used before $\mathrm{Cu}$ analysis. Recently, a applied dispersive liquid-liquid microextraction was used for separation/extraction of ions from liquid samples. In this study, USADC-LLME based on AMOXC was used for efficient extraction of $\mathrm{Cu}$ ions in human biological samples before determination by F-AAS. The hydrophobic ionic liquid was used for simple separating of $\mathrm{Cu}$ -
AMOXC from blood samples.

\section{Experimental}

\subsection{Instrumental}

The spectra GBC 906 double beam atomic absorption spectrophotometer was used for copper determination (FAAS, GBC, Model; Plus 906, Australia). The air-acetylene as fuel gas based on background correction was selected for F-AAS. The light of HCL adjusted on burner by vertical and horizontal positions. The Avanta software of spectra was used for collecting data. The copper hollow cathode lamp (HCL, slit=0.7) with wavelength of $327.4 \mathrm{~nm}$ and current of $4.0 \mathrm{~mA}$ was adjusted in vertical and horizontal position. For copper analysis, the limit of detection, working range was obtained $0.06 \mathrm{mg} \mathrm{L}^{-1}$ and $0.2-24.0 \mathrm{mgL}^{-1}$, respectively by F-AAS. All samples as minimum volume were used by auto-sampler injector $(0.5-5 \mathrm{~mL})$. The $\mathrm{pH}$ values of the solutions were measured by a digital $\mathrm{pH}$ meter (Metrohm 744), especially in human samples. All samples were shaken with Thermo accessory as mixer (250 rpm, USA) and centrifuged with Thermo fisher (1000-4500 rpm, USA).

\subsection{Reagents}

The ultra-trace reagents with analytical grade such as; $\mathrm{HNO} 3, \mathrm{HCl}, \mathrm{NaOH}$, copper salt and acetone solutions were purchased from Merck (Darmstadt, Germany). The pure AMOXC as amoxicillin trihydrate: potassium clavulanate (4:1) was purchased from sigma, Germany (Product N: SMB00607, Batch $\mathrm{N}: 128 \mathrm{M} 4800 \mathrm{~V}, 75 \%$ AMOX and less than $15 \%$ clavulanic acid and less than $15 \%$ water) (Fig.1). The $\mathrm{Cu}(\mathrm{II})$ stock standard solution was prepared as nitrate salt of $1000 \mathrm{mg} \mathrm{L}^{-1}(\mathrm{ppm})$ solution in $1 \%$ $\mathrm{HNO}_{3}$. The standard solutions were prepared daily by dilution of the standard solution of $\mathrm{Cu}$ (II) by ultra-pure water(UPW). High purity distilled water had already prepared from Millipore (Bedford, USA). 1-Ethyl-3-methylimidazolium acetate (CAS N: 143314-17-4), 1-Ethyl-3-methylimidazolium tetrafluoroborate (CAS N: 143314-16-3), 1-Ethyl-3methylimidazolium hexafluorophosphate (CAS N: 155371-19-0), and 1-butyl-2,3-dimethylimidazolium 


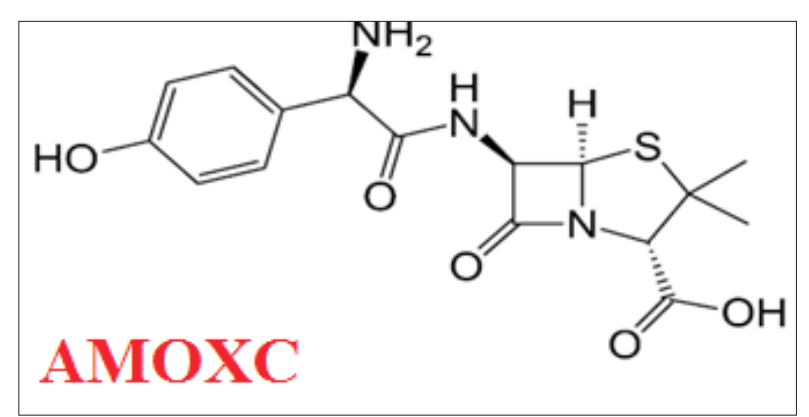

Fig. 1. Schema of amoxicillin trihydrate: potassium clavulanate

hexafluorophosphate ([BDMIM] $\left[\mathrm{PF}_{6}\right]$ ) as a hydrophobic ionic liquids were was selected for separation AMOXC from blood sample. The T-X100 with analytical grade were purchased from Merck Co., Darmstadt, Germany. The $\mathrm{pH}$ was adjusted with buffer solutions (Merck, Germany). Sodium phosphate and citric acid was used for phosphate citrate buffer for $\mathrm{PH}=2.0-7.5$.

\subsection{Sample preparation}

The glasses were washed with a $\mathrm{HNO}_{3}$ solution $(0.5 \mathrm{M})$ for at least $24 \mathrm{~h}$ and thoroughly rinsed 10 times with ultra-pure water. For sampling, $20 \mathrm{ml}$ of samples of blood were collected from subjects and control peoples ( $\mathrm{N}=30$, men, $30-55$ age). $10 \mathrm{~mL}$ of blood sample mixed with heparin (pure, 20 micro liter) and storage in low temperature. Then, $10 \mathrm{~mL}$ of blood samples were stay at the room temperature for 30 minutes to coagulate and then centrifuged at 3000 rpm for 5 minutes. Next, serums were separated by a sampler. Plasma was also prepared by procedure by centrifuging process. The human blood/serum samples were maintained at $-20{ }^{\circ} \mathrm{C}$ up to $72 \mathrm{~h}$. In humans with low sample volume of blood, it diluted up to $20 \mathrm{~mL}$ and then was used. The dilution factor was calculated after determination copper in blood samples.

\subsection{Procedure}

By USA-DC-LLME procedure, the $10 \mathrm{mg}$ of pure AMOXC powder (15 micro molar conc.) mixed with ionic liquid ([BMIM][PF6], IL, $0.1 \mathrm{~g}$ ) in present of 500 micro liter of acetone/ethanol, then, the mixture was injected to $10 \mathrm{ml}$ of serum blood sample at human $\mathrm{pH}=7.2$ (Fig.2). After $5 \mathrm{~min}$ shaking time, the hydrophobic ionic liquid BMIM] [PF6] was separated by centrifuging at $3500 \mathrm{rpm}$ for $4 \mathrm{~min}$ in conical glass tube. The upper liquid phase separated by auto-sampler accessory $(1-100 \mathrm{~mL})$ and remained phase (IL-AMOXC/Cu ${ }^{2+}$ ) were backextracted from IL phase by decreasing $\mathrm{pH}$ up to 1 $\left(\mathrm{HNO}_{3}, 0.5 \mathrm{M}, 0.5 \mathrm{~mL}\right)$. Finally the concentration of $\mathrm{Cu}^{2+}$ ions was simply determined by F-AAS after dilution with DW up to $1 \mathrm{~mL}$.

\section{Results and discussion}

For extraction copper from blood samples all parameters ( $\mathrm{pH}$, sample volume, amount of AMOXC and IL) must be optimized. The serum, blood, urine samples was prepared from patients with copper disease such as multiple sclerosis. After tuning $\mathrm{pH}$ with favorite buffers, the sample determines by ultrasound assisted-dispersive centrifuge liquidliquid micro extraction (USA-DC-LLME) coupled to F-AAS.

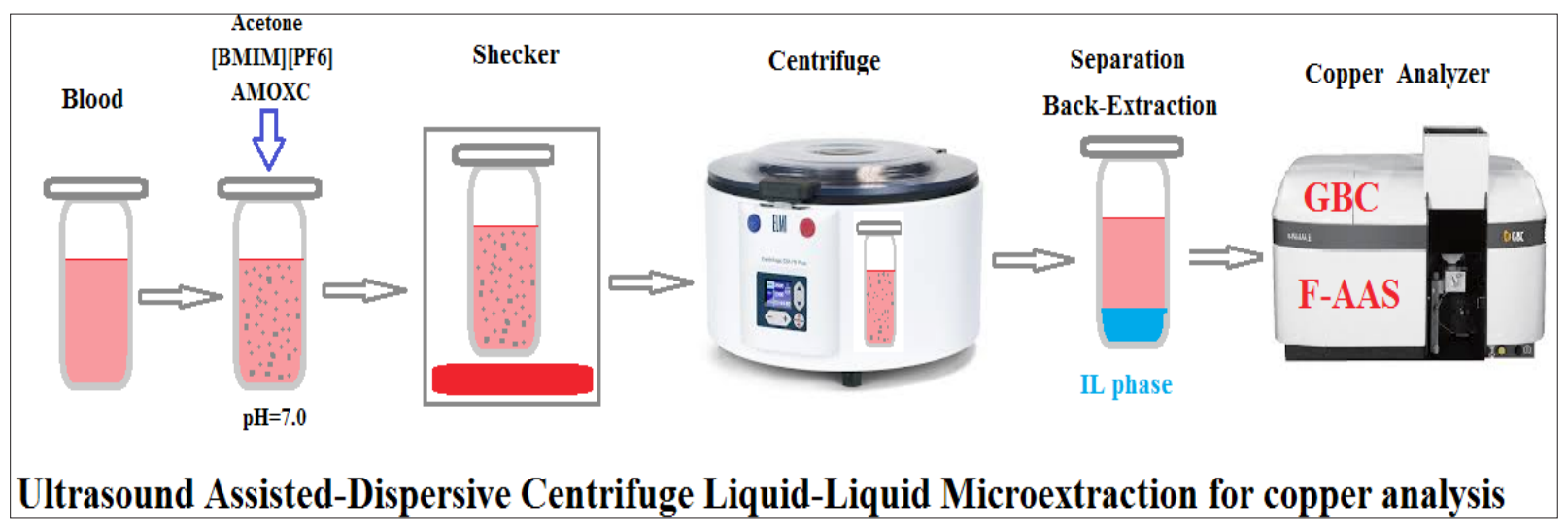

Fig. 2. The copper extraction from blood samples based on AMOXC by USA-DC-LLME 


\subsection{PH effect}

The effect of sample $\mathrm{pH}$ on complexation of $\mathrm{Cu}$ (II) ions on AMOXC was studied for $0.2 \mathrm{mg} \mathrm{L}^{-1}$ and $2.0 \mathrm{mg} \mathrm{L}^{-1}$ of $\mathrm{Cu}(\mathrm{II})$ (lower limit of quantification; LLOQ and upper limit of quantification; ULOQ) from different $\mathrm{pH}$ 1-12. The complexation of AMOXC-Cu was depended on the $\mathrm{pH}$ of solutions and function group of ligand. The results showed, the maximum extraction of $\mathrm{Cu}$ (II) was achieved in human $\mathrm{pH}$ (7.0), and the recovery values for $\mathrm{Cu}$ (II) were below $5 \%$ in acidic or basic $\mathrm{pH}$. The extraction mechanism of $\mathrm{Cu}(\mathrm{II})$ ions with $\mathrm{AMOXC}$ was highly referred to $\mathrm{pH}$ and complex formation between $\mathrm{Cu}(\mathrm{II})$ ions and dative sulfur bonding of AMOXC (Fig. 3). The sulfur groups can be deprotonated (:S$\mathrm{R}$ ) at wide range of $\mathrm{pH}$ from 6 to 9 . The extraction efficiency of $\mathrm{Cu}$ (II) at $\mathrm{pH}$ values below 6 and upper of 8 cannot occurred due to similarity charge or precipitation of hydroxyl copper $\left(\mathrm{Cu}(\mathrm{OH})_{2}\right)$.

\subsection{Sample volume effect}

The sample volume in one of the important factors which must be optimized for $\mathrm{Cu}$ extraction from blood samples by AMOXC. As evaluation extraction efficiency, different volumes between $1.0-30 \mathrm{~mL}$ of blood and serum samples was examined and optimizes in $\mathrm{pH}=7$. The results showed us that the maximum recovery for copper extraction based on AMOXC was achieved for less than $12 \mathrm{~mL}$ for human blood samples and less than $17 \mathrm{~mL}$ of standard solutions. Therefore, $10 \mathrm{~mL}$ and $15 \mathrm{~mL}$ of sample volume was selected as optimum point for copper extraction for blood and water samples, respectively by USA-DC-LLME procedure (Fig.4).

\subsection{AMOXC effect}

The amount of ligand is very important for copper extraction in blood samples, so, the concentration of AMOXC in human samples must be studied for high extraction. For this purpose, the vary concentration between 1-50 micro molar concentration of AMOXC was prepared and used for evaluation of copper extraction in blood/standard samples by USA-DCLLME procedure. The experimental results showed, the high extraction of copper was obtained with more than 15 micro molar of AMOXC in $10 \mathrm{~mL}$ of samples ( $\sim 10 \mathrm{mg}$ pure powder) by USA-DC-LLME procedure (Fig. 5). Also, the extraction efficiency more than $97 \%$ was made by 12 micro molar of AMOXC concentration in $10 \mathrm{~mL}$ of water samples. First, $10 \mathrm{mg}$ of pure AMOXC powder mixed with ethanol/acetone $(0.5 \mathrm{~mL})$ and then added to $0.1 \mathrm{~g}$ of IL in $2 \mathrm{~mL}$ syringe. After shacking, the mixture injected to $10 \mathrm{~mL}$ of blood samples. The extraction efficacy was decreased about $74.6 \%$ when the mixture added step by step without shacking.

\subsection{Ionic liquid effect}

Separation process for $\mathrm{AMOXC}-\mathrm{Cu}$ from liquid samples (blood, standard solution) is very difficult.

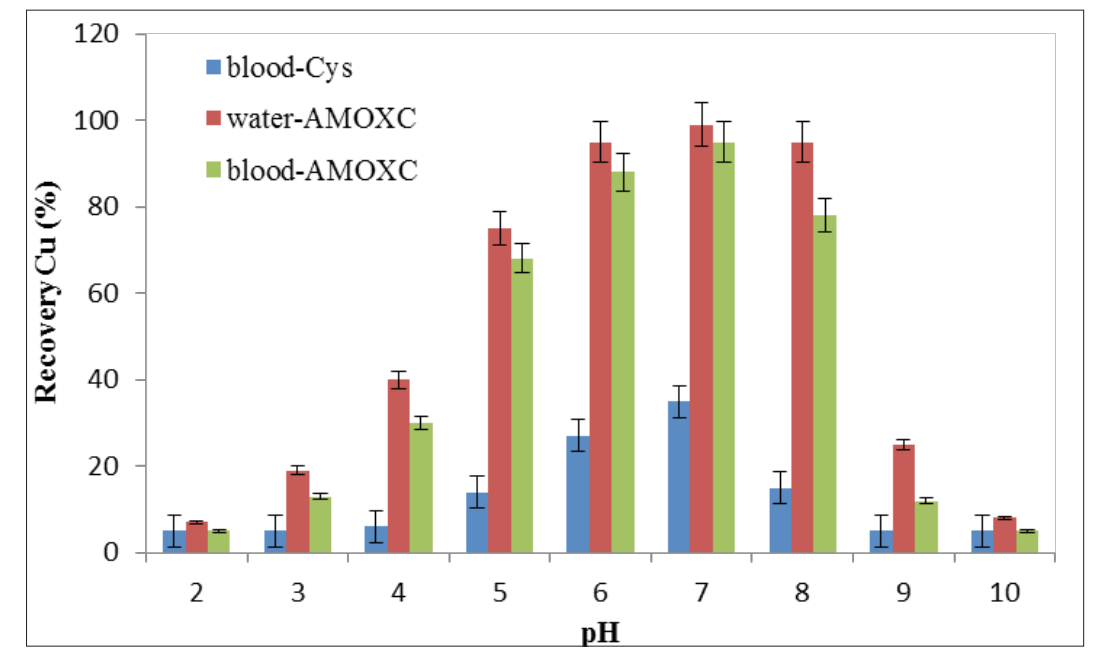

Fig. 3. The effect of $\mathrm{pH}$ on copper extraction based on AMOXC by USA-DC-LLME procedure 


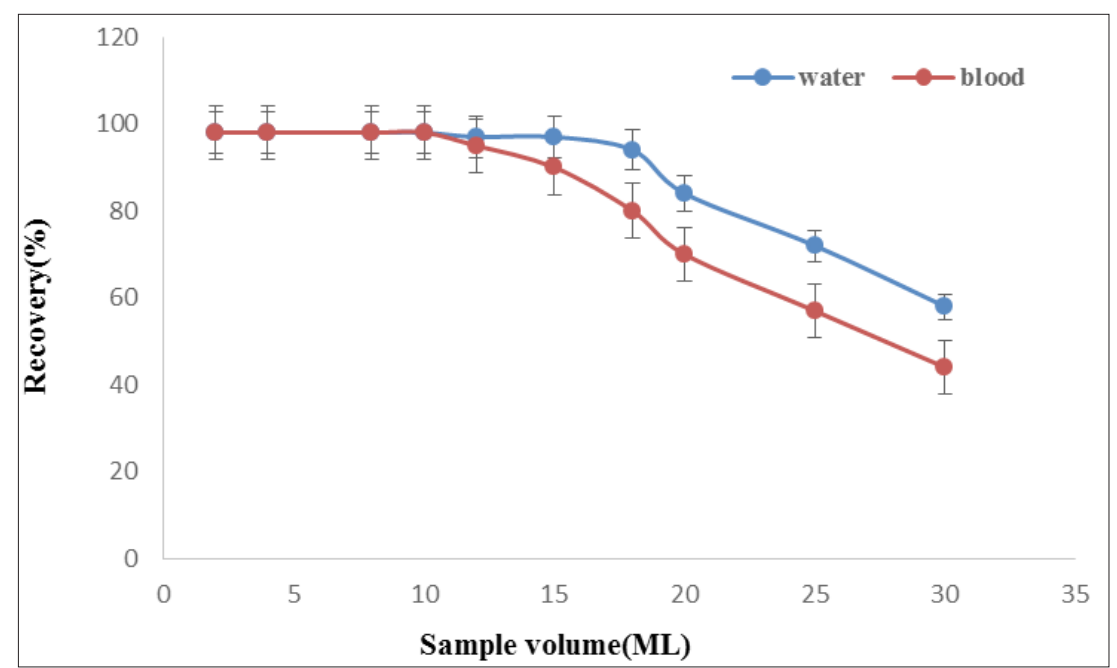

Fig. 4. The effect of sample volume on copper extraction based on AMOXC by USA-DC-LLME procedure

The different techniques with filter, centrifuging and organic solvents was used for separation ligands from liquid phase. Recently, the benign solvents as green solvents (IL) was introduced in many papers. In this study we used different hydrophobic ionic liquids for separation processes in blood samples. The different volumes or gram $(0.05-0.3 \mathrm{~g})$ of 1-Ethyl-3-methylimidazolium acetate, 1-Ethyl-3methylimidazolium tetrafluoroborate, 1-Ethyl-3methylimidazoliumhexafluorophosphate, and1-butyl2,3-dimethylimidazolium hexafluorophosphate $[\mathrm{BDMIM}]\left[\mathrm{PF}_{6}\right]$ as a hydrophobic ionic liquids were was selected for separation AMOXC from blood sample. Based on results, $0.1 \mathrm{~g}$ of $[\mathrm{BDMIM}]\left[\mathrm{PF}_{6}\right]$ has more extraction efficiency as compared to others (Fig.
6). The 1-Ethyl-3-methylimidazolium acetate and 1-Ethyl-3-methylimidazolium tetrafluoroborate had lower recovery because of solubility in liquid phase and missed of IL. The1-Ethyl-3-methylimidazolium hexafluorophosphate as hydrophobic IL can be separated copper-AMOXC from blood samples but has lower recovery (85\%) as compared to [BDMIM] $\left[\mathrm{PF}_{6}\right]$ with $(97.8 \%)$.

\subsection{Interference ions study}

Many ions such as $\mathrm{Zn}^{2+}, \mathrm{Mn}^{2+}, \mathrm{Na}^{+}, \mathrm{K}^{+}, \mathrm{HCO}_{3}^{-}, \mathrm{SO}_{3}^{-}$, $\mathrm{Fe}^{2+}, \mathrm{Co}^{2+}$, exist in water or blood samples and can be effected on complexations of copper with AMOXC in presence of interference ions. The complexation copper depended on power of ligand and competition

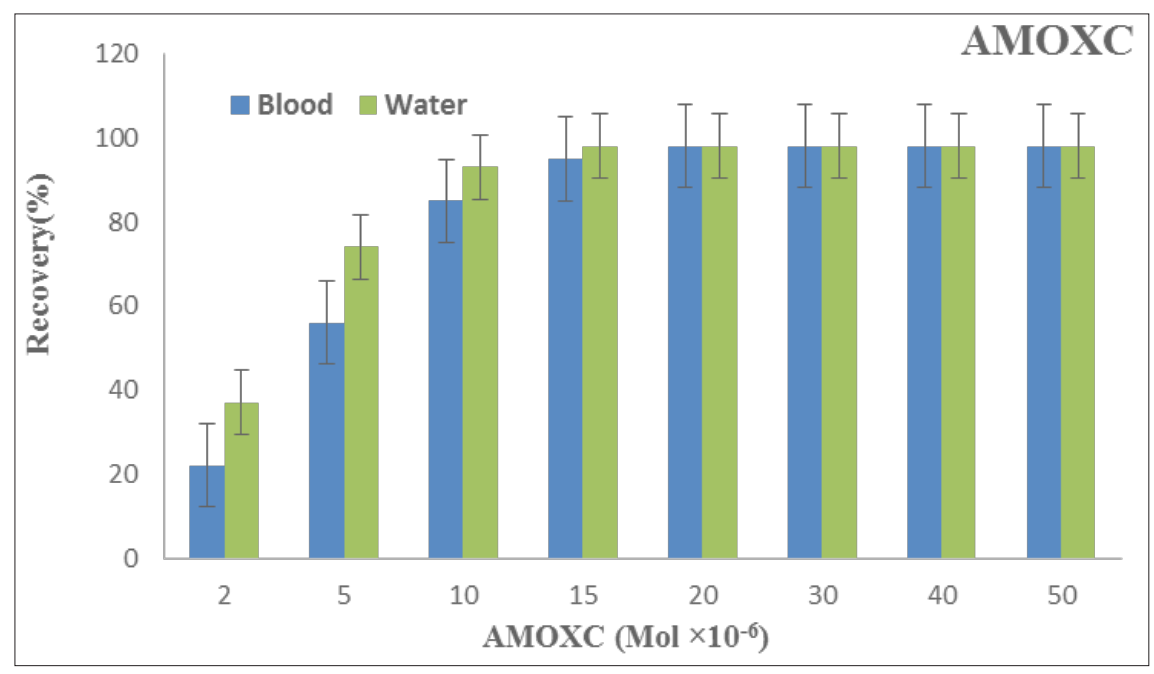

Fig. 5. The effect of AMOXC concentration by USA-DC-LLME procedure 
of ions in different $\mathrm{pH}$. So, in optimized $\mathrm{pH}$ many ions had no effect on extraction process, but some of them may be done. Therefore the effect of important ions which was bonding with amino acids or proteins was studied. The recovery of copper extraction based on AMOXC in presence of different concentration of 1-4 mg L $\mathrm{L}^{-1}$ of cations and anions was evaluated by USA-DC-LLME procedure. As selectivity of determination of F-AAS, the concentration of other ions can't reported. So, the recovery was checked as effect of interference ions. The results showed, the interference ions had no effect on complexation processes of copper - AMOXV by USA-DC-LLME procedure (Table 1).

\subsection{Validation procedure}

The methodology of copper extraction must be validated by different technologies. By spiking of blood, serum, urine, plasma samples, the favorite recovery more than $95 \%$ was achieved for LLOQ and ULOQ range. So, the USA-DC-LLME procedure was validated for copper complexation based on AMOXC (Table 2). In addition, ET-AAS coupled with microwave digestion was used for evaluation of purposed procedure after dilution samples up to $100 \mathrm{~mL}(1: 10)$ (Table 3). As intra-day and interday studies, the mean copper concentration based on AMOXC in subjects and control groups $(\mathrm{N}=30$, men, 30-55 age) was checked by USA-DC-LLME procedure. The results showed no significance difference between subjects and control groups with favorite $p$-value (Table 4). The mean concentration of copper in control groups were a little higher than $\mathrm{Cu}$ blood subjects. The regression analysis and t-test were achieved between $\mathrm{Cu}$ in subject and control groups. There were a correlation $(0.45<\mathrm{r}$ $<0.5)$ between blood of subject and control groups. $(p$-value $<0.001)$.

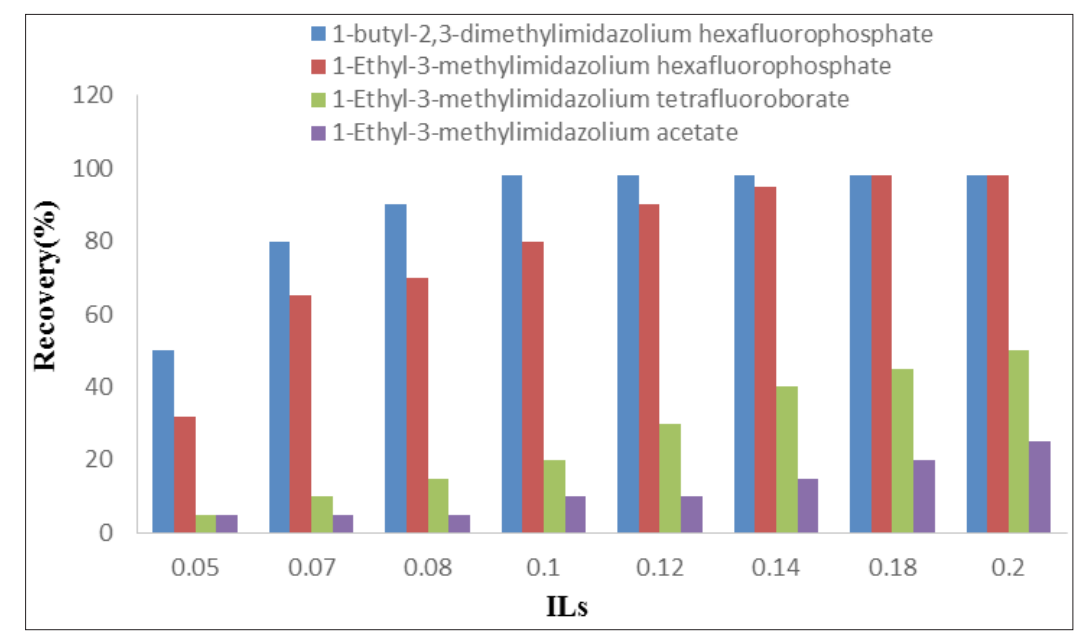

Fig. 6. The effect of different ILs on copper separation based on AMOXC by USA-DC-LLME procedure

Table 1. Effect of interfering ions on the extraction recovery of $\mathrm{Cu}$ (II) ions by USA-DC-LLME procedure

\begin{tabular}{|c|c|c|c|c|}
\hline \multirow[b]{2}{*}{ Foreign Ions } & \multicolumn{2}{|c|}{ Concentration ratio $\left(\mathrm{C}_{\text {interferent ion }} / \mathrm{C}_{\mathrm{Cu} 2+}\right)$} & \multicolumn{2}{|c|}{ Recovery (\%) } \\
\hline & Standard & Blood & Standard & Blood \\
\hline $\mathrm{K}^{+}, \mathrm{Na}^{+}, \mathrm{Li}^{+}, \mathrm{Cl}^{-}, \mathrm{F}^{-} . \mathrm{Mg}^{2+}, \mathrm{Ca}^{2+}$ & 1200 & 1000 & 97.5 & 96.8 \\
\hline $\mathrm{Co}^{2+}, \mathrm{Ni}^{2+}$ & 900 & 700 & 98.2 & 97.3 \\
\hline $\mathrm{Pb}^{2+}, \mathrm{Ag}^{+}$ & 600 & 500 & 97.6 & 97.9 \\
\hline $\mathrm{Zn}^{2+}, \mathrm{Mn}^{2+}$ & 700 & 600 & 95.5 & 98.4 \\
\hline $\mathrm{Fe}^{2+}, \mathrm{V}^{3+}, \mathrm{As}^{3+}, \mathrm{Mo}^{3+}$ & 850 & 800 & 97.0 & 96.8 \\
\hline $\mathrm{Cd}^{2+}, \mathrm{Al}^{3+}$ & 800 & 550 & 98.2 & 97.3 \\
\hline $\mathrm{Hg}^{2+}$ & 1000 & 900 & 96.5 & 95.7 \\
\hline $\mathrm{CO}_{3}^{2-}, \mathrm{SO}_{3}^{2-}$ & 950 & 600 & 99.1 & 98.5 \\
\hline
\end{tabular}




\section{Conclusions}

A simple Pharmacology and biology method based on USA-DC-LLME was used for evaluating of AMOXC for copper extraction in human blood samples. The results demonstrated that AMOXC can decreased copper concentration in blood samples in efficient time. On the other hands amino acids and proteins was also complexed with copper and caused to decrease copper extraction by AMOXC. So, the AMOXC competed with amino acids and proteins for extraction copper and other metals at $\mathrm{pH}$ 7.2. In addition, the antibiotics such as $A M O X C$ can treat the bacterial infections but they can decrease essential metals $(\mathrm{Cu})$ in biological matrixes and cause disease in humans. By purposed procedure, the copper extracted with $\mathrm{AMOXC}$ at $\mathrm{pH}=7$ and determined by F-AAS. The 1-butyl2,3-dimethylimidazolium hexafluorophosphate ([BDMIM] $\left[\mathrm{PF}_{6}\right]$ as hydrophobic IL was used for separation of $\mathrm{Cu}$ from liquid phase. In optimized conditions, the low LOD and RSD\% values as well as good working ranges $\left(0.02-2.58 \mathrm{mg} \mathrm{L}^{-1}\right)$ and high recoveries caused to consider as a recent innovative procedure.

\section{Acknowledgements}

The authors wish Department of Pharmacology Tehran University of Medical Sciences and the Kermanshah University of Medical Sciences for supporting of this work.

\section{References}

[1] G.F. Nordberg, B.A. Fowler, M. Nordberg, Handbook on the Toxicology of Metals, (Fourth ed.), Academic Press, 2014.

[2] H.P. Roeser, G.R. Lee, S. Nacht, G.E. Cartwright, The role of caeruloplasmin in iron metabolism, J. Clin. Invest., 49 (1970) 2408-2417.

[3] S. Catalani, M. Paganelli, M. Enrica Gilberti, L. Rozzini, F. Lanfranchi, A. Padovani, P. Apostol, Free copper in serum: An analytical challenge and its possible applications, J. Trace Elem.Med. Biol., 45 (2018)176-180.

Table 2. Spiking of human samples based on AMOXC for copper extraction by USA-DC-LLME coupled to F-AAS

\begin{tabular}{|c|c|c|c|}
\hline Sample & $\operatorname{Added}\left(\mathrm{mg} \mathrm{L}^{-1}\right)$ & ${ }^{*}$ Found $\left(\mathrm{mg} \mathrm{L}^{-1}\right)$ & Recovery (\%) \\
\hline \multirow[t]{2}{*}{ Blood } & ------- & $0.884 \pm 0.043$ & -------- \\
\hline & 0.8 & $1.675 \pm 0.072$ & 98.8 \\
\hline \multirow[t]{2}{*}{ Serum } & -------- & $1.226 \pm 0.058$ & -------- \\
\hline & 1.2 & $2.384 \pm 0.094$ & 96.5 \\
\hline \multirow[t]{2}{*}{ Urine } & -------- & $0.431 \pm 0.022$ & -------- \\
\hline & 0.4 & $0.838 \pm 0.039$ & 101.7 \\
\hline \multirow[t]{2}{*}{ Plasma } & -------- & $0.362 \pm 0.024$ & -------- \\
\hline & 0.3 & $0.657 \pm 0.028$ & 98.3 \\
\hline
\end{tabular}

Table 3. Comparing of ETAAS/digestion with USA-DC-LLME procedure coupled to F-AAS

\begin{tabular}{lccccc}
\hline & & ET-AAS & USA-DC-LLME & Recovery (\%) & Recovery (\%) \\
Sample & Added & Microwave & F-AAS & ET-AAS & F-AAS \\
\hline Blood & ------- & $1.002 \pm 0.055$ & $0.985 \pm 0.048$ & ------- & ------- \\
\multirow{3}{*}{ Serum } & 1.0 & $1.977 \pm 0.112$ & $1.981 \pm 0.094$ & 97.5 & 99.6 \\
& ------- & $1.212 \pm 0.063$ & $1.197 \pm 0.053$ & ------- & ------ \\
\hline
\end{tabular}

Table 4. The mean copper concentration based on AMOXC in subjects and control groups (N=30) by USA-DCLLME procedure

\begin{tabular}{lccccc}
\hline Sample & \multicolumn{2}{c}{ Control group (30n) } & \multicolumn{2}{c}{ Patient group (30n) } & r \\
\hline & Intra-day & Inter-day & Intra- day & Inter day & \\
Blood & $1.34 \pm 0.05$ & $1.27 \pm 0.06$ & $1.16 \pm 0.04$ & $1.19 \pm 0.05$ & 0.58 \\
Serum & $1.41 \pm 0.06$ & $1.46 \pm 0.07$ & $1.25 \pm 0.05$ & $1.26 \pm 0.06$ & 0.61 \\
\hline
\end{tabular}


[4] R. Squitti, Copper in Alzheimer's disease: a metaanalysis of serum plasma, and cerebrospinal fluid studies, J. Alzheimers Dis., 24 (2011) 175-185.

[5] B.S. Choi, W. Zheng, Copper transport to the brain by the blood-brain barrier and blood-CSF barrier, Brain Res., 1248 (2009) 14-21.

[6] Y.U. Fengxiang, P. Gong, Z. Hu, Y. Qiu, Y. Cui, X. Gao, H. Chen, J. Li, Cu(II) enhances the effect of Alzheimer's amyloid- $\beta$ peptide on microglial activation, J. Neuroinflamm., 12 (2015)122.

[7] S. Bolognin, L. Messori, D. Drago, C. Gabbiani, L. Cendron, P. Zatta, Aluminum, copper, iron and zinc differentially alter amyloid-A $\beta 1-42$ aggregation and toxicity, Int. J. Biochem. Cell Biol., 43 (2011) 87785.

[8] X.Y. Choo, L. Alukaidey, A.R. White, A. Grubman, Neuroinflammation and copper in Alzheimer's disease, Int. J. Alzheimers Dis., 2013 (2013) 145345.

[9] LM Gaetke, copper: toxicological relevance and mechanisms, Arch. Toxicol., 88 (2014) 1929-1938

[10] S. Radi, S. Tighadouini, M. Bacquet, S. Degoutin, Y. Garcia, New hybrid material based on a silicaimmobilised conjugated $\beta$-ketoenol-bipyridine receptor and its excellent $\mathrm{Cu}$ (II) adsorption capacity, Anal. Method., 8 (2016) 6923-6931.

[11] S. Tighadouini, S. Radi, M. Bacquet, S. Degoutin, M. Zaghrioui, S. Jodeh, I Warad, Removal efficiency of $\mathrm{Pb}$ (II), $\mathrm{Zn}$ (II), Cd (II) and $\mathrm{Cu}$ (II) from aqueous solution and natural water by ketoenol-pyrazole receptor functionalized silica hybrid adsorbent, Sep. Sci. Technol., 52 (2017) 608-621.

[12] A. Prkić, I. Mitar, J. Giljanović, V. Sokol, P. Bošković, I. Dolanc, T. Vukušić, Comparison of Potentiometric and ETAAS Determination of Copper and Iron in Herbal Samples, Int. J. Electrochem. Sci., 13 (2018) $9551-9560$.

[13] S. Catarino, A. S. Curvelo-Garcia, Determination of copper in wine by ETAAS using conventional and fast thermal programs: Validation of analytical method, Atom. Spect. Norwalk Connecticut, 26 (2005) 73-78.

[14] E. A. Al-Harbi, M. S. El-Shahawi, Square waveanodic stripping voltammetric determination of copper at a bismuth film/glassy carbon electrode using 3-[(2-Mercapto-Vinyl)-Hydrazono]- 1,3-dihydroindol, Electroanal., 30 (2018) 1583-1885.

[15] J. F. Ayala-Cabrera, M. J. Trujillo-Rodríguez, V. Pino, Ó. M. Hernández-Torres, A. M. Afonso, J. Sirieix-Plénet, Ionic liquids versus ionic liquidbased surfactants in dispersive liquid-liquid microextraction for determining copper in water by flame atomic absorption spectrometry, Inter. J. Environ. Anal. Chem., 96 (2016) 101-118.

[16] N. Bader, H. Hasan, A. EL-Denali, Determination of $\mathrm{Cu}, \mathrm{Co}$, and $\mathrm{Pb}$ in selected frozen fish tissues collected from Benghazi markets in Libya, Chem. Methodol., 2 (2018) 56-63

[17] M. Soylak, O. Ercan, Selective separation and preconcentration of copper (II) in environmental samples by the solid phase extraction on multiwalled carbon nanotubes, J. Hazard. Mater., 168 (2009) 1527-1531.

[18] C. Duran, A. Gundogdu, V. N. Bulut, M. Soylak, L. Elci, H. B. Sentürk, M. Tüfekci, Solid-phase extraction of Mn (II), Co (II), Ni (II), Cu (II), Cd (II) and $\mathrm{Pb}$ (II) ions from environmental samples by flame atomic absorption spectrometry (FAAS), J. Hazard. Mater., 146 (2007) 347-355.

[19] Y. M. Hao, C. Man, Z. B. Hu, Effective removal of Cu2+ ions from aqueous solution by aminofunctionalized magnetic nanoparticles, J. Hazard. Mater., 184 (2014) 392-399.

[20] Y. T. Zhou, H. L. Nie, C. B. White, Removal of Cu2+ from aqueous solution by chitosan-coated magnetic nanoparticles modified with aketoglutaric acid, J. Colloid Interf. Sci., 330 (2009) 29-37.

[21] S. Golkhah, H. Zavvar Mousavi, H. Shirkhanloo, A. Khaligh, Removal of $\mathrm{Pb}(\mathrm{II})$ and $\mathrm{Cu}(\mathrm{II})$ Ions from Aqueous Solutions by Cadmium Sulfide Nanoparticles, Int. J. Nanosci. Nanotechnol., 13 (2017) 105-117.

[22] A. Sarı, M. Tuzen, D. Citak, M. Soylak, Adsorption characteristics of $\mathrm{Cu}$ (II) and $\mathrm{Pb}$ (II) onto expanded perlite fromaqueoussolution, J. Hazard. Mater., 148 (2007) 387-394.

[23] S. A. Arain, T. G. Kazi, H. I. Afridi, M. Shahzadi Arain, A. H. Panhwar, N. Khan, J. A. Baig, F. Shah, A new dispersive liquid-liquid microextraction using ionic liquid based microemulsion coupled with cloud point extraction for determination of copper in serum and water samples, Ecotoxicol. Environ. Safe., 126 (2016) 186-192.

[24] A.T. Bisgin, Surfactant-Assisted Emulsification and Surfactant-Based Dispersive Liquid-Liquid Microextraction Method for Determination of $\mathrm{Cu}(\mathrm{II})$ in Food and Water Samples by Flame Atomic Absorption Spectrometry, J. AOAC Inter., 102 (2019) 1516-1522. 